\title{
Orientação argumentativa e Cognição: a Dinâmica de Forças no debate acerca dos rolezinhos
}

\author{
Argumentative orientation and Cognition: Force Dynamics \\ in the debate over the rolezinhos
}

\section{Paulo Roberto Gonçalves-Segundo}

Universidade de São Paulo - São Paulo - São Paulo - Brasil

\begin{abstract}
Resumo: Nosso objetivo, neste artigo, é analisar a argumentação desenvolvida em dois artigos, publicados na Folha de S. Paulo, que representam posições polarizadas sobre uma série de encontros adolescentes - os rolezinhos - ocorridos em shopping centers em dezenas de cidades brasileiras em 2013 e 2014. Para isso, tecemos um diálogo entre a Linguística Cognitiva e os Estudos Argumentativos, que relaciona o princípio cognitivo de Dinâmica de Forças (Talmy, 2000) à estruturação da argumentação. Pudemos depreender três eixos que organizam as posições ideológicas assumidas nos artigos: a concepção dos shoppings como espaços privados ou públicos; a importância do direito à propriedade em comparação ao direito à manifestação; e a visão dos rolezinhos como eventos orientados para 0 entretenimento ou para a contestação social. Os primeiros componentes de cada eixo são instanciados harmonicamente no primeiro texto (T1) para construir uma conceptualização de perigo, na qual os adolescentes agem como um Antagonista que bloqueia a tendência dos 'verdadeiros frequentadores' de comprar e divertir-se no local. Os últimos componentes de cada eixo também se correlacionam e estruturam a argumentação do segundo texto (T2), que se baseia na concepção de que a lei deva ser um Agente que garanta a tendência do Agonista 'adolescente' de se manifestar, uma vez que tais jovens já são conceptualizados como bloqueados pela desigualdade social, e a sociedade é tomada como tendo o dever de incluir tais pessoas.
\end{abstract}

Palavras-chave: dinâmica de forças, argumentação, rolezinho, contestação social, discurso midiático, Linguística Cognitiva, movimento social.

\begin{abstract}
This paper aims to analyze the argumentation developed in two articles, published in Folha de S. Paulo, that represent polarized stances about a series of teenage meetings - known as rolezinhos - held in several malls in dozens of Brazilian cities in 2013 and 2014. To do so, we establish a theoretical dialogue between Cognitive Linguistics and Argumentation Studies, that relates the cognitive principle of Force Dynamics (Talmy, 2000) to the structuration of argumentation. We could determine three axes that organize the ideological positions in the articles: the conception of shopping malls as private or public spaces; the importance of the right to property in comparison to the right to manifest; and the view of the rolezinhos as events oriented towards entertainment or social contestation. The first components of each axis are harmonically deployed in the first text (T1) in order to build a conceptualization of danger, whereby the teenagers act as an Antagonist that blocks the tendency of the 'true costumer' to buy and have fun in the mall. The second components of each axis are also correlated and structure the argumentation of the second text (T2), which bases itself in a conception that the law should be an Agent which guarantees the tendency of the Agonist 'young people' to manifest, since these teenagers are already conceptualized as being blocked by social inequality, and the society is taken as having the duty of including these people.
\end{abstract}

Key-words: force dynamics, argumentation, rolezinho, social contestation, media discourse, Cognitive Linguistics, social movement. 


\section{Introdução}

No final de 2013 e no início de 2014, os rolezinhos - encontros de jovens realizados, primariamente, em shopping centers de grandes centros urbanos brasileiros - tornaram-se notícia nacional e centro de calorosas polêmicas na mídia desse país, mobilizando especialistas de distintas áreas, que tendiam a polarizar os eventos como manifestações orientadas ora pela diversão, ora pela contestação social. Dentre o jornalismo impresso, a Folha de S. Paulo destacou-se por apresentar uma cobertura extensiva da prática, abordada em editoriais, artigos de opinião, notícias, reportagens e cartas do leitor.

Nosso objetivo, neste trabalho, é analisar a argumentação desenvolvida em dois artigos de opinião - publicados nesse jornal e assinados por juristas de posições antagônicas em relação à concessão de uma liminar que proibiu a realização dos rolezinhos em shoppings de São Paulo -, atentando para as formas pelas quais os encontros são representados nos textos, especialmente no que tange à relação entre os jovens, os shoppings, a sociedade e o aparelhamento do Estado.

Para isso, exploraremos um diálogo teórico, já iniciado por autores como Oakley (2005) e Dishong (2004), entre a Linguística Cognitiva (LC) e as teorias da argumentação, a destacar Toulmin (2006 [1958]), Breton (2003) e van Eemeren, Grootendorst \& Henkemans (2002). No caso específico deste artigo, abordaremos detidamente o princípio cognitivo de Dinâmica de Forças (DF), proposto por Talmy (2000), procurando examinar seu papel na orientação argumentativa dos textos.

Organizamos o texto do seguinte modo: na primeira seção, expomos algumas considerações sobre a LC; na segunda, tratamos do princípio de DF; na terceira, procedemos à análise dos textos selecionados; e, por fim, tecemos considerações finais acerca dos padrões cognitivo-argumentativos dos textos e do potencial de integração da LC com as teorias discursivas para a análise da (re)construção de sentido.

\section{A Linguística Cognitiva e a análise discursivo-argumentativa}

Segundo Geeraerts (2010), a LC consiste em um conjunto de abordagens que examina a linguagem na correlação entre sua dimensão conceptual e sua dimensão interacional, buscando compreender a arquitetura do sistema linguístico entendido como uma rede contínua (não discreta) de construções - a partir do reconhecimento da realidade social e cultural da cognição situada.

Langacker (2008) ressalta que a LC assume uma perspectiva não modular da linguagem. Nesse sentido, propõe, por um lado, a construção como um elemento primitivo da linguagem, que consiste, grosso modo, em uma correlação entre forma (morfossintaxe e fonologia) e significado (semântica, pragmática e discurso) que ativa conceptualizações complexas multimodais em termos de conhecimento de fundo (frames, Modelos Cognitivos Idealizados, esquemas imagéticos, ideologias) e, por outro, a existência de uma associação intrínseca entre a linguagem e as outras capacidades cognitivas humanas, como atenção, memória, categorização e perspectivação.

Por conseguinte, a língua é vista como "um sistema adaptativo complexo, uma estrutura fluida, constituída, ao mesmo tempo, de padrões mais ou menos regulares e de outros que estão em permanente emergência, mercê de necessidades cognitivas e/ou intercomunicativas" (BYBEE, 2010 apud CUNHA; BISPO; SILVA, 2013, p. 20). Em outros termos, ela não é apenas um repositório de conhecimento empregado no uso, mas também é um produto desse uso. Isso significa que, para a LC, a dimensão discursiva é constitutiva da linguagem e não pode ser negligenciada para uma compreensão global sobre a produção e interpretação de sentido e sobre a configuração gramatical.

Geeraerts (2010) afirma que o aspecto que une as diversas abordagens cognitivistas consiste na centralidade da significação, o que aponta, segundo Ferrari (2011), para a prevalência da Semântica e da Pragmática nas análises. Para a LC, o significado é: 
a. flexível e dinâmico, uma vez que é moldável e moldado, interacionalmente, por cada interlocutor, na medida em que está em contínuo processamento e reprocessamento e, portanto, sempre aberto a reorientações, mudanças e confrontações;

b. enciclopédico, já que sua construção envolve redes de conhecimentos culturais e ideológicos associados que colaboram para a compreensão e para a elaboração de uma dada versão da realidade. Assim, um lexema como aborto pode invocar, na rede, em maior ou menor grau de probabilidade, associações com assassinato ou pecado, para determinados grupos, e com liberdade de escolha e emancipação feminina, para outros;

c. perspectivado, visto que é resultado de nossa experiência com a realidade, o que implica que a LC não concebe uma relação objetiva entre o significado e o mundo, rejeitando postulados vericondicionais.

A partir de Talmy (2000), De Mulder (2007) propõe cinco esquemas conceptuais universais estruturantes da linguagem, expostos, sinteticamente, na sequência. São eles:

a. a estrutura configuracional, que diz respeito ao arranjo de elementos espaço-temporais para a formação de cenas em que entidades de uma dada natureza assumem relações entre si;

b. a localização do ponto de perspectiva, que concerne a um ponto de vista a partir do qual o conceptualizador constrói a cena, assumindo uma posição fixa ou móvel ao longo do tempo;

c. a distribuição de atenção, que envolve o modo pelo qual os elementos de uma cena, concebida a partir de uma dada perspectiva, recebem maior ou menor atenção, dirigindo o percurso de conceptualização;

d. a dinâmica de forças, que se refere à interação de forças exercidas pelos elementos constitutivos do complexo cênico, estando associada à experiência de movimentação e de pressão humana;

e. o estado cognitivo, que abarca 0 comprometimento do falante ou o estatuto de realidade ligado à cena a partir do ponto de vista do conceptualizador.
Neste trabalho, enfocaremos o princípio de Dinâmica de Forças, concebido como um princípio cognitivo fundamental nas línguas naturais, que opera tanto na estruturação gramatical quanto na construção discursiva.

\section{A Dinâmica de Forças na linguagem}

Talmy (2000) afirma que a DF apresenta papel significativo na estrutura linguística, abarcando uma diversidade de fenômenos em vários níveis de análise, desde subconjuntos de conjunções, preposições, verbos e modalizadores, até componentes do nível discursivo, que envolvem o direcionamento de padrões argumentativos e de expectativas.

Lakoff (1987, p. 14) concebe-a como um esquema imagético, ou seja, como "um padrão dinâmico e recorrente de interação perceptual e programação motora que dá coerência e estrutura à experiência humana", constituindo-se, assim, na "matéria-prima" para a formação de Modelos Cognitivos Idealizados. Esses, por sua vez, são entendidos como meios de organização do conhecimento derivados da nossa capacidade de abstrair padrões pertinentes de cenas e de eventos, proporcionando-nos a competência para interpretar situações e reagir adequadamente em face das distintas práticas sociais em que estamos envolvidos (CIENKI, 2007).

Croft e Cruse (2004) destacam a FORÇA ${ }^{1}$ como um esquema imagético central. Ferrari (2011), baseada nesses autores, arrola, em associação a esse esquema, as experiências de EQUILÍBRIO, FORÇA CONTRÁRIA, COMPULSÃO, RESTRIÇÃO, HABILIDADE, BLOQUEIO e ATRAÇÃO. Tais esquemas podem ser metaforicamente elaborados, extrapolando as experiências de movimento e de pressão que estão na sua origem pré-conceptual corporeada para os campos intrapsicológico, por um lado, e interpsicológico/social, por outro. Assim, torna-se possível que o esquema se manifeste em distintos

1 Convenciona-se, na área, grafar esquemas imagéticos e seus componentes em versalete (small caps). 
componentes da gramática das línguas, permitindo que alcancemos uma diversidade de objetivos e realizemos, de formas variadas, nossas intenções comunicativas.

Talmy (2000) apresenta uma categorização pertinente do fenômeno, aplicável para a análise gramatical e discursiva. $O$ esquema envolve, basicamente, quatro componentes: a. as entidades de força; b. a tendência intrínseca de ação ou repouso dessas forças; c. o seu equilíbrio; e d. a resultante de sua interação.

As entidades de força consistem no Agonista (AGO) e no Antagonista (ANT), noções conceptuais que podem ser realizadas por distintas funções sintáticas e papéis temáticos na estrutura oracional. O AGO consiste na entidade cuja tendência de força - ação ou repouso - se encontra em foco. Tal tendência será mantida a menos que a ação de um ANT possa revertê-la. Assim, o ANT consiste na entidade que entra em oposição ao AGO, podendo ou não impor sua tendência em relação a ele, a depender do equilíbrio projetado, ou seja, de ser mais forte ou mais fraco que esse.

No quadro a seguir, expomos as representações básicas que auxiliarão no procedimento analítico:

Quadro 1. Resumo das representações sobre o esquema imagético de Dinâmica de Forças

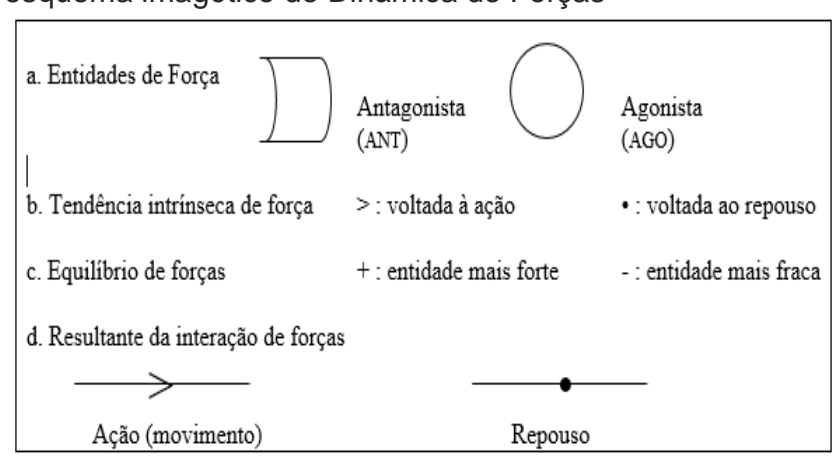

Fonte: baseado em Talmy (2000, p. 414)

Dependendo da forma de interação, vários padrões podem emergir. Para este trabalho, destacaremos a causação, a concessão, o bloqueio, o desengajamento e a permissão.

A causação consiste na interação entre um ANT mais forte - prototípica, mas não exclusivamente, em movimento - que impele o AGO, fraco e em repouso, à ação. Em outros termos, sem a ação do ANT, o AGO permaneceria no seu estado inicial. Trata-se de um padrão verificável em modais deônticos, estruturas causativas, conjunções causais e consecutivas, dentre outros. O esquema a seguir nos permite visualizar seu funcionamento:

i.

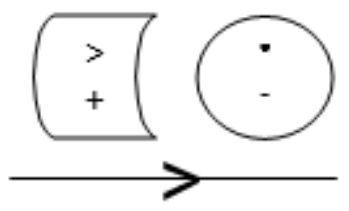

A concessão configura-se em uma interação de forças na qual o ANT não tem força o suficiente para reverter a tendência do AGO. Observamos tal padrão em conectivos concessivos, adversativos e em adjuntos modais de contra-expectativa. Vejamos o esquema, que ilustra o exposto a partir de uma resultante de repouso - poderia ser de ação também, caso as tendências estivessem opostas:

ii.

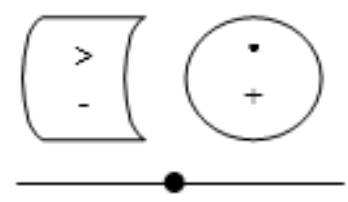

O bloqueio - no fundo, uma causação de repouso, destacada por sua produtividade no corpus - constitui-se em uma dinâmica na qual o ANT, mais forte e em repouso, inibe a tendência do AGo à ação. Trata-se, portanto, de casos de proibição, incapacidade e interdição, visualizáveis no esquema (iii):

iii.

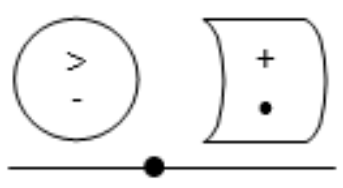

Por fim, a permissão é um padrão de forças no qual o ANT, mais forte, prototipicamente em repouso, não entra em confronto com o AGO, que tende ao movimento, possibilitando, então, que este 
exerça sua tendência. No desengajamento, por sua vez, temos um AGENTE EXTERNO — representado por uma flecha vertical - que é responsável por desengajar o ANT do seu confronto com o AGO, o que caracterizaria, sem sua participação, um caso de bloqueio. A resultante em ambos os casos é a mesma. Vejamos os esquemas:
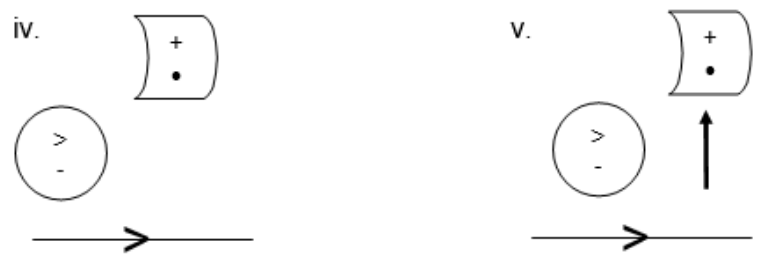

Devemos ressalvar que nem sempre a interação entre forças perfila uma resultante, havendo situações em que o destino final do AGo não se encontra explícito na construção, conforme mostraremos na seção posterior. Ademais, nem sempre a resultante é tida como real, podendo consistir em uma projeção autoral (como ocorre em modais, por exemplo) ${ }^{2}$. Isso posto, passamos à análise dos dados.

\section{Análise do corpus: a Dinâmica de Forças e a orientação argumentativa}

Os textos selecionados para a análise consistem em dois artigos de opinião publicados no dia 14 de janeiro de 2014, na seção Opinião, da Folha de S. Paulo, sob a autoria de dois importantes juristas. O primeiro dos textos (T1), assinado por Mauro Rodrigues Penteado e intitulado Tais como são, os 'rolezinhos' atentam contra direitos coletivos, assume uma posição contrária à realização dos encontros nos shopping centers, ao passo que 0 segundo, assinado por Pedro Abramovay (T2) e denominado Liminar que proíbe encontro assegura 'direito à segregação', condena a atitude de proibição

\footnotetext{
2 Para maiores detalhes sobre a permeabilidade da Dinâmica de Forças na gramática e no discurso, ver Gonçalves-Segundo (2015).
}

dos rolezinhos e discute o conflito entre o direito de propriedade e o de manifestação ${ }^{3}$.

Iniciemos a análise pelo contraste entre os títulos, uma vez que ambos já sinalizam a orientação argumentativa do texto e apresentam esquemas de forças. As construções atentar (contra), proibir e assegurar consistem em recursos linguísticos que apontam para possíveis interações entre forças.

No caso de atentar (contra), o AGO direitos coletivos, que tende ao movimento, ou seja, à continuidade na sociedade, na medida em que consiste em um valor coletivo desejável, é confrontado pela força do ANT os 'rolezinhos', que tende ao repouso, isto é, à subversão do status quo vigente, com potencial de bloquear a vigência de tais direitos. Nesse sentido, os encontros são construídos como elementos que podem desestabilizar a ordem coletiva, tese que será defendida ao longo do artigo. Destacamos, contudo, que a forma verbal não perfila uma resultante, de modo que não podemos afirmar, pelo título, que a voz autoral concebe os rolezinhos como eventos que, de fato, anularam e/ou anulam direitos coletivos; há apenas o confronto e o risco.

No segundo título, podemos depreender dois esquemas de força em interação: um de bloqueio (iii) ${ }^{4}$ e um de desengajamento (v). O primeiro desses padrões é ativado pela forma verbal proíbe, que ativa um ANT forte, em repouso, capaz de minar o potencial de ação do AGo fraco. No caso, a liminar consiste nesse ANT que interdita os jovens rolezeiros de se encontrarem, o que aponta para uma resultante de não realização do evento. Já o esquema de desengajamento é ativado pelo verbo assegurar. No caso, a liminar consiste no AGENTE EXTERNO - a flecha vertical do esquema (v) - que viabiliza que um AGO genérico, não explícito, torne efetiva sua tendência de segregar os rolezeiros ${ }^{5}$. No caso, o ANT

\footnotetext{
3 Aconselhamos uma leitura prévia dos textos, anexos a este artigo, para que se acompanhe melhor a análise.

4 Os números indicados, ao longo do texto, em algarismos romanos minúsculos, inseridos entre parênteses, remontam aos esquemas apresentados na seção 2.

5 Nos dois casos em análise, os grupos nominais indicados para AGO não são explicitados no título. Eles são, na verdade, inferidos da leitura dos artigos e integram o frame dos elementos nominalizados encontro e segregação, que pressupõem agentes - os jovens rolezeiros, no primeiro caso, e a elite e os proprietários de lojas e de shopping centers, no
} 
- igualmente implícito - capaz de exercer o bloqueio seria a própria lei. Em outros termos, o aparato jurídico que deveria barrar a segregação (por parte da elite e dos proprietários de lojas e de shopping centers) está, na verdade, permitindo-a.

Nesse sentido, depreendemos que Abramovay (T2) entende como natural a ocorrência dos rolezinhos. Por conseguinte, a liminar é vista como um instrumento oficial que vem de encontro à aplicação do direito de manifestação garantido também pela lei. É a essa aparente contradição - a utilização de um instrumento legal para sobrepor-se a uma outra garantia legal - que consistirá no foco da argumentação do autor.

O articulista inicia sua argumentação por meio de uma estratégia de enquadramento do real (BRETON, 2003), que visa ao estabelecimento de condições para que um argumento seja aceitável, de forma a tornar a tese convincente, e, posteriormente, atualiza uma construção de caráter sintomático (VAN EEMEREN; HOUTLOSSER; HENKEMANS, 2007) orientada a convencer o leitor de que o caso em análise consiste em uma instância da realidade anteriormente enquadrada. Tal processo é alimentado por inúmeros recursos de força. Vejamos:

(1) São raríssimos os casos em que a decisão do juiz não deve analisar com cuidado dois direitos distintos. I Por isso é tão difícil a tarefa de julgar. A lei provoca contradições entre direitos. Quase sempre. "O caso dos "rolezinhos" não foi diferente. (T2)

O conectivo Por isso marca, na construção, uma relação causativa (i), na qual a raridade de casos em que não se deve analisar cuidadosamente direitos distintos configura-se em um ANT forte, que torna difícil a tarefa do AGO juiz de exercer sua função: julgar. Em outros termos, a concepção de que julgar é difícil é resultado da normalidade da análise de aspectos contraditórios entre direitos distintos. Tratase, portanto, de um argumento de causalidade (BRETON, 2003; VAN EEMEREN;

último. A análise dos processos de FORÇA poderia ter sido feita com base nas nominalizações. Isso mascararia, contudo, os agentes humanos implicados em ambas as atividades, o que é indesejável em uma análise discursivo-argumentativa.
GROOTENDORST; HENKEMANS, 2002), ao qual subjaz a interação de componentes de força. Tal estratégia promove enquadramento do real, uma vez que cria um contexto em que se vê como parte inerente do trabalho do magistrado a consideração da natureza contraditória dos direitos, de forma que a atitude de ignorar tal complexidade passa a ser vista como desviante, passível, portanto, de censura/crítica e resultado de possível incompetência ou parcialidade.

Tal estratégia permite, então, que a voz autoral vincule o caso em análise ao esquema anteriormente construído, inserindo, assim, os rolezinhos no âmbito das decisões em que competem direitos contraditórios. Segundo van Eemeren; Houtlosser; Henkemans (2007), ocorre, neste excerto, um uso do argumento sintomático, definido como aquele que propõe uma relação de concomitância ou identificação entre um evento ou indivíduo e um conjunto de propriedades. Em outros termos, o autor transfere ao caso dos encontros de jovens as características e propriedades que definem a decisão jurídica prototípica. Entretanto, essa visão da contradição de direitos, que é a base do enquadramento realizado em T2, é marginal senão, ignorada - no artigo de Penteado (T1). Observemos:

(2) Por mais que nos solidarizemos com nossa juventude humilde que busca espaços para se relacionar e dar vazão ao seu amor e alegria, não é possível apoiá-la nessa onda recente de "rolezinhos" marcados em shoppings centers e outros locais privados com destinação específica. I É triste a ausência de opção de lazer para nossos jovens de camadas mais pobres. No entanto, os "rolezinhos", tais como vêm sendo marcados, atentam contra os direitos individuais e coletivos assegurados pela Constituição Federal. I Isso sem falar no direito também constitucionalmente garantido à propriedade e à livre iniciativa (arts. 1으. inc. IV, 5, "caput" e 170). Daí porque estão corretas as liminares concedidas pelo Judiciário aos shoppings - que estabeleceram multa aos participantes. (T1)

O excerto apresenta inúmeras instâncias de DF. Entretanto, enfocaremos apenas aquelas que marcam explicitamente o posicionamento autoral relativo às causas do rolezinho e a relação entre os 
eventos, a população e a lei. Iniciemos pelo esquema de bloqueio (iii) ativado pela construção não é possível.

Segundo Halliday (2004), a oração matriz não é possível constitui-se em uma forma modal explícita e objetiva, por simular que o comprometimento ou a responsabilização autoral pelo conteúdo proposicional não parte do próprio produtor. Em termos cognitivistas, trata-se de uma estratégia que permite ao conceptualizador não se assumir como o ANT responsável pela imposição sobre o AGO, atribuindo tal papel a um conjunto de evidências ou fatos potencialmente relevantes para a situação, fortes o suficiente para o exercício da causação ou do bloqueio.

Em termos concretos, o apoio à onda de rolezinhos em locais privados é construído como a resultante esperada da ação do AGO implícito população/sociedade, de modo que podemos depreender que a voz autoral concebe essa atitude como uma das alternativas válidas de posicionamento em face da questão. Entretanto, pela inscrição do recurso modal, tal alternativa é bloqueada por um ANT não autoral ou impessoal, que só será especificado nos parágrafos seguintes - o fato de os encontros atentarem contra os direitos individuais e coletivos constitucionais, por um lado, e contra os direitos à propriedade e à livre iniciativa, por outro. Desse modo, temos um ANT que consiste em um conjunto de fatos e de evidências que deveria bloquear o AGO população de realizar sua tendência de apoio (TALMY, 2000; DE MULDER, 2007). Trata-se, portanto, de uma construção em que ocorre uma projeção metafórica do domínio físico-social para o argumentativo-inferencial.

Essa ausência de apoio, causada pelo atentado contra os direitos mencionados, é vista, entretanto, como passível de contra-argumentação. Essa potencial refutação (TOULMIN, 2006 [1958]; TOULMIN; RIEKE; JANIK, 1984 [1978]) é marcada pelos operadores de contra-expectativa por mais que e no entanto. Em uma interpretação ligada à Dinâmica de Forças, um contra-argumento representa um ANT, que atua - primária, mas não exclusivamente - no sentido de bloquear os fatos, evidências ou argumentos AGO, que tendem à ação, isto é, a uma dada conclusão. A concessão opera, argumentativamente, no sentido de se reconhecer a refutação, tornando-a, contudo, fraca em relação ao argumento-base. Desse modo, seu potencial de modificar a conclusão estabelecida é invalidado, o que garante a ratificação da tendência ou do ponto de vista que se traçava.

Nesse sentido, tanto a solidarização com a juventude humilde que busca espaços para se relacionar e dar vazão a seu amor e alegria, quanto a tristeza decorrente da ausência de opções de lazer para as camadas mais pobres são previstas como refutações à proibição dos rolezinhos e consistem, para a voz autoral, em argumentos verossímeis, ligados ao pathos (PERELMAN; OLBRECHTSTYTECA, 2002 [1958]), com potencial de sensibilizar a coletividade no sentido de apoiar o movimento. Em termos mais específicos, podemos afirmar que se trata de uma estratégia de envolvimento e de solidarização (GONÇALVES-SEGUNDO, 2011), que atua no sentido de mitigar possíveis reações de resistência à argumentação autoral, devido à partilha de afetos entre o articulista e possíveis leitores discordantes, na medida em que ele se insere no âmbito da coletividade passível de conexão, conforme a primeira do plural permite atestar - por mais que nos solidarizemos [...]. Vemos, portanto, um forte recurso de construção de empatia, fenômeno importante no gerenciamento do processo de convencimento e de persuasão (GONÇALVESSEGUNDO; RIBEIRO, 2016).

Entretanto, ao construir a solidarização e a tristeza sob o efeito de recursos de contraexpectativa, a voz autoral acaba projetando-as como ANT fracos, incapazes de impedir a ação do AGO implícito população rumo à 'inevitável' conclusão de que os rolezinhos atentam contra os direitos individuais e coletivos e de que eles não podem ser, portanto, apoiáveis. Em outros termos, a voz autoral estabelece uma hierarquia de valores (REBOUL, 2004 [1998]), na qual o direto à propriedade e à livreiniciativa, somados a uma visão bem parcial de 
direitos individuais e coletivos - que exclui os jovens rolezeiros - torna-se mais relevante que o direito à manifestação e à busca por espaços para reunião. A perspectiva é comercial e orientada ideologicamente ao segregacionismo social.

É justamente na denúncia dessa parcialidade que Abramovay (T2) promove sua argumentação quando trata da liminar, assumindo, assim, uma hierarquia de valores diferenciada, na qual o direito à livre circulação e à manifestação, além da igualdade de acesso, consistem em valores superiores ao direto à propriedade. Observemos:

(3) O próprio juiz admitiu que havia um conflito de direitos. O direito de manifestação dos jovens da periferia e o de propriedade dos donos do shopping. O juiz diz que o direito de propriedade deve prevalecer porque há outros espaços mais apropriados para manifestações. II Essa resposta do juiz veio em uma liminar. O que significa que apenas um lado foi ouvido: o lado dos donos de shopping. E só isso pode explicar o fato de se imaginar que o "rolezinho" pode ser feito nas ruas. II O que pedem os "rolezinhos"? Sem danificar o patrimônio e sem registros de furtos, jovens da periferia querem circular por espaços que the são proibidos. Espaços segregados. Segregados, até agora, não pela força do direito, mas porque não há nada ali que Ihes seja acessível. I O grande problema da decisão é que ela assegura um direito à segregação. (T2)

Embora haja, de modo análogo ao excerto (2), uma série de esquemas de forças que subjazem à conceptualização dos quatro parágrafos selecionados, desejamos destacar as causações (i) e os bloqueios (iii), uma vez que elas estão envolvidas na construção das razões para a realização dos encontros.

O conectivo porque assinala uma relação causativa argumentativo-inferencial que projeta como ANT a existência de espaços alternativos apropriados para manifestações, evidência construída como forte o suficiente para mobilizar o AGO juiz a decidir pela necessidade prevalência do direito de propriedade, a resultante. Tal argumento seria relevante, na visão autoral, se a questão do espaço fosse marginal no âmbito dos rolezinhos. Entretanto, para Abramovay (T2), trata-se de aspecto central, conforme fica explícito em Jovens da periferia querem circular por espaços que Ihe [sic] são proibidos. O modal de inclinação querer (HALLIDAY, 2004) apresenta um jogo de DF diferenciado, não analisado por Talmy (2000). Ele pressupõe dois estados - um de bloqueio (iii), real, e um de permissão (iv), contrafactual - e a possibilidade de transição de um para o outro, o que configura desengajamento (v).

No estado inicial/real, o AGO, mais fraco, embora com tendência à ação, é bloqueado por circunstâncias externas ou internas - o ANT - que constrangem sua ação. No caso, o AGo consiste nos jovens de periferia, ao passo que o ANT, ainda que não especificado, pode ser associado à desigualdade social. O estado final/contrafactual seria, por sua vez, o momento em que o AGENTE EXTERNO desengajaria o ANT bloqueador, viabilizando condições para que o AGO manifeste sua tendência de circular pelo shopping. Esse AGENTE seria a própria sociedade ou ainda a lei, que deveria garantir o direito de reunião e de acesso, desengajando o fosso da desigualdade, que segrega o AGO jovens da periferia, conforme o autor deixa claro no segmento final do parágrafo em análise - Segregados, até agora, não pela força do direito, mas porque não há nada ali que lhes seja acessível. Assim, podemos assumir que a forma verbal querer opera na tensão entre o estado de bloqueio vigente e o vislumbre de sua suspensão, de modo que podemos considerá-la como um caso de interação sociodinâmica e potencial de forças.

O que a voz autoral realiza, portanto, é apresentar uma definição de rolezinho. Para Abramovay (T2), não há outro local para a realização desses encontros, porque se trata de um movimento de ocupação de espaços segregados pela desigualdade social. O argumento do juiz responsável pela liminar torna-se inválido nessa concepção, na medida em que se dissocia (BRETON, 2003; REBOUL, 2004) a noção de apropriado: para o magistrado, o local apropriado é aquele que, em termos de espaço físico e de segurança, comporta uma alta quantidade de jovens, ao passo que, para o articulista, o local apropriado é aquele em que os rolezeiros podem manifestar seu direito de reunião, um espaço desejado por eles e que lhes é bloqueado 
pela falta de renda e/ou pela desigualdade e, após a liminar, pela própria lei, o que oficializa a exclusão.

Essa questão espacial é fundamental na defesa das teses de ambos os juristas e é central que ela seja observada em contraste. Vejamos o quadro a seguir:

Quadro 2. A concepção do espaço shopping no âmbito dos rolezinhos

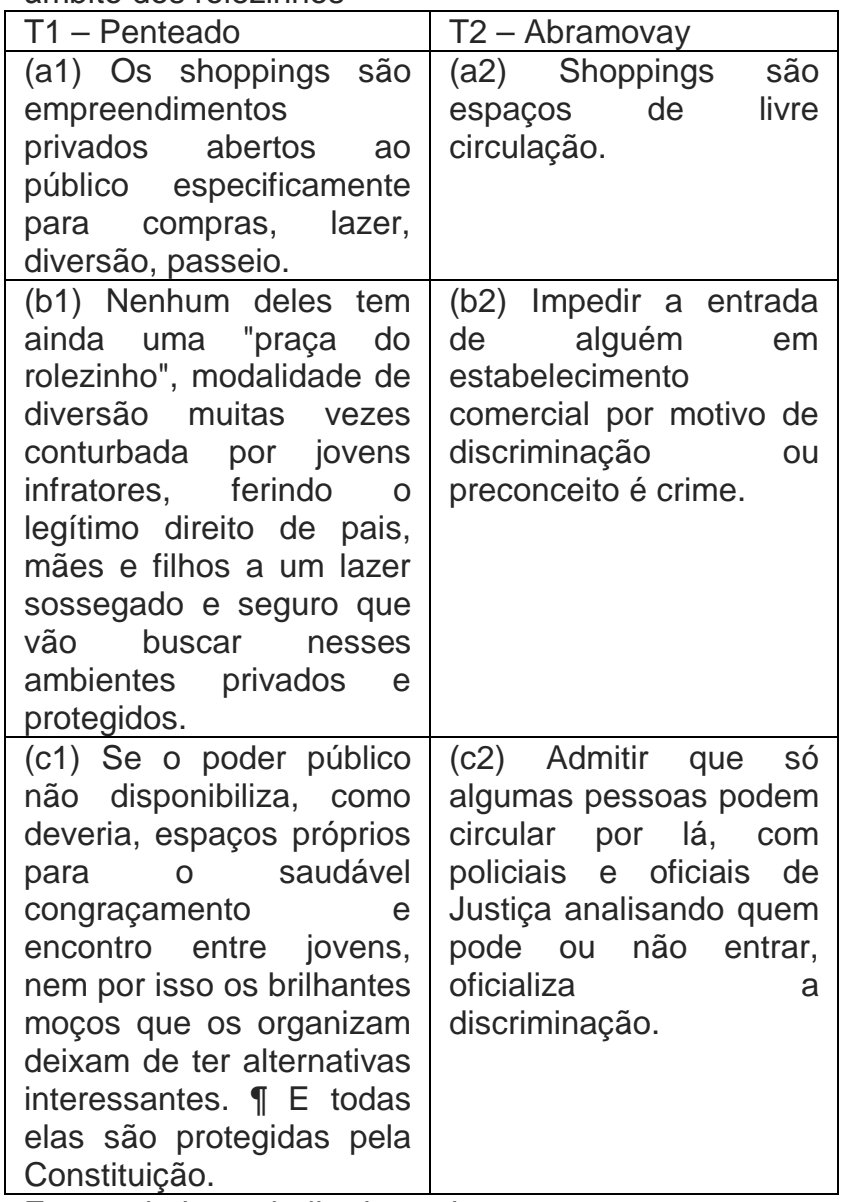

Fonte: dados trabalhados pelo autor

As construções (a) apontam para dois modelos diferenciados de shopping center, que - embora não apresentem, na superfície linguística, interação entre forças - apoiam-se em conceptualizações subjacentes em termos de permissão (iv) como sustentáculo para justificar as teses defendidas. Assim, vemos que, em ambas, não há barreiras explícitas às pessoas. Entretanto, há diferenciação no que tange ao tipo de pessoa que pode circular livremente no estabelecimento comercial. Nesse sentido, o que ocorre, em T1, é a seleção de AGO. Só não há bloqueio aos atores sociais associados às atividades elencadas de comprar, entreter-se, divertir- se e passear, aos outros, há interdição, o que sinaliza a presença de um ANT forte, que tende ao repouso, com poder para engajar seletivamente O AGO, decidindo se o confronta ou não, com base em suas intenções.

Temos, portanto, definições diferentes que embasam a defesa dos argumentos de ambos os juristas. Para Reboul (2004 [1998]), a definição consiste em um argumento quase lógico que se calca em uma identificação, impondo uma determinada perspectiva sobre a realidade. Assim, em (a1), é o caráter privado que é enfatizado, ao passo que, em (a2), é a dimensão pública, sem filtro de AGO, que é destacada, o que pressupõe distinções na implementação de forças e consequências diferenciadas para as ações dos jovens.

Penteado (T1) associa, por um lado, o caráter privado à proteção e, por outro, os rolezeiros a atitudes potencialmente criminosas, em um jogo de forças ligado a bloqueio (iii). Os rolezeiros são construídos como ANT fortes, cujo comportamento tende a bloquear o AGO pais, mães e filhos de usufruir de um lazer sossegado e seguro, a tendência de comportamento esperada nesses ambientes. Em outros termos, os jovens são capazes de reverter o caráter protetor dos shopping centers. Assim, verificamos uma concepção complementar, não explicitada linguisticamente, de que os shoppings são ANT fortes, capazes de bloquear a incidência do AGO violência ou, ainda melhor, de atores sociais violentos, em seu domínio. Nesse sentido, a permissão à realização dos rolezinhos faria com que - ANT shopping desengajasse 0 AGO, O que acarretaria a invasão do crime no ambiente, conforme podemos depreender da construção conturbada por jovens infratores. Como corolário, a liminar consiste em instrumento de segurança para os "verdadeiros" frequentadores dos shoppings e em garantia do funcionamento do estabelecimento no que tange à sua "vocação" fundamental: vender, entreter e divertir. É curioso notar, contudo, a desconsideração pelo fato de os rolezeiros também desfrutarem do ambiente para as mesmas atividades. Em consequência disso, é possível associar as razões pelas quais a liminar foi 
concebida como derivadas de atitudes potencialmente preconceituosas.

Para Abramovay (T2), entretanto, crime é a realização do bloqueio (iii) via liminar, conforme podemos observar em (b2) e (c2). Se o shopping é um espaço de livre circulação, não deve haver bloqueios, ou seja, ANT que resistam à tendência de ação do AGO. Entretanto, a liminar irá atuar como um ANT forte, justamente por se tratar de um recurso legal que autoriza esse cerceamento. $\mathrm{O}$ direito à propriedade teria, assim, sobrepujado o direito à manifestação e ao livre acesso, conforme já assinalamos. Tal constatação é relevante, na medida em que, para o autor, o que parecer ser, de fato, justo é que a lei atue como um AGENTE que garanta o desengajamento de potenciais ANT — ANT como esse juiz, por meio da liminar, ou como os proprietários de estabelecimentos comerciais, por meio do acirramento da segurança - no que tange à liberdade de movimento/ação do AGo jovens. Assim, em T2, a liminar é medida de autoritarismo, exclusão e discriminação em relação aos rolezeiros.

A solução seria, então, para Penteado (T1), a realização dos encontros em ambientes alternativos, conforme podemos observar em (c1), uma vez que, nesse caso, se garantem a suposta liberdade e a segurança de todos. É crucial verificarmos, a propósito, que a Constituição é construída como AGENTE de proteção dos direitos e, portanto, como constituinte de um esquema imagético em que o AGO fraco jovens pode exercer sua tendência pela suspensão do caráter bloqueador de possíveis ANT, desde que, é claro, não seja no shopping.

Destacamos também que há, no excerto, uma mecânica de concessão e causação modal, na medida em que, por um lado, a voz autoral, como ANT, posiciona-se como autoridade para impulsionar o AGO governo a disponibilizar espaços para os jovens - como deveria - , reconhecendo sua insuficiência, mas, por outro, constrói tal ausência como um fato ou evidência antagônica que não possui força o bastante para levar os rolezeiros, AGO, a usar o shopping como local para encontros. A insistência na existência de lugares alternativos revela, reiteradamente, a desconsideração, em T1, do aspecto de contestação social que é atribuído, em T2, aos eventos.

\section{Considerações finais}

Neste artigo, analisamos a relação entre o princípio cognitivo de Dinâmica de Forças e a orientação argumentativa em textos que instanciam posições antagônicas em relação a uma liminar que proibia a realização de rolezinhos nos shoppings de São Paulo.

Assim, mostramos de que modo a análise das interações entre forças permite um exame pormenorizado, de um ponto de vista microlinguístico e cognitivo, de uma série de procedimentos e estratégias argumentativas, como o enquadramento do real, a definição, o argumento causal, a refutação, a concessão e a hierarquia de valores.

A partir disso, pudemos depreender que havia três grandes pontos de confronto ideológico nos textos: a concepção de shopping como espaço público ou privado, a preponderância do direito à manifestação ou do direito à propriedade, e a visão do rolezinho como evento de contestação social ou como encontro de pura diversão. Subjacente a esses aspectos, que atuam como argumentos que sustentam as teses dos autores a favor e contra a liminar, encontraram-se diferentes concepções de força:

a. O direito à manifestação e ao acesso, conceptualizado como AGO, tem sua tendência a movimentar-se/agir garantida pelo AGENTE EXTERNO lei, que desengaja o ANT direito à propriedade. Tratase, portanto, de um esquema de inclusão oficial. A este, associa-se uma interação de forças na qual o AGO jovens é bloqueado pelo ANT inacessibilidade ou desigualdade social, em uma resultante de repouso, responsável pela ativação da representação de exclusão implícita ou não oficial, de caráter indesejado. A liminar atua no sentido de reverter o desengajamento oficial que garante a inclusão, oficializando a segregação, de modo a tornar o direito à propriedade e, portanto, o desejo das elites comerciárias como mais forte que a liberdade dos 
jovens, bloqueando-a. Tal condição é concebida como negativa e como um elemento causador de instabilidade social em um contexto que prima pela emergência de espaços de convivência. Tal é a concepção de Abramovay, em T2, que argumenta a favor da inclusão/integração social.

b. O direito à propriedade, conceptualizado como AGO fraco, tem seu movimento garantido pela liminar, um AGENTE EXTERNO que desengaja o direito à manifestação ou ao livre acesso, o ANT. Tal dinâmica é sustentada por uma relação causativa calcada na existência de lugares alternativos para a realização dos encontros, ANT forte que impele o juiz, AGO, a conceder a liminar. Temos, assim, a exclusão oficial, que se materializa, por um lado, no ato de o ANT oficiais de justiça e polícia expulsarem o AGO jovens, que tende a integrar o encontro, e, por outro, no ato de multar os participantes. Nesse sentido, a liminar é também o AGENTE EXTERNO que desengaja o ANT rolezeiros, permitindo ao AGO "verdadeiros" frequentadores do shopping realizar a sua tendência: divertir-se, passear e consumir em segurança. Tal é a concepção subjacente a T1, artigo escrito por Penteado, que favorece uma visão segregacionista dos grupos sociais.

Isso posto, podemos concluir que a análise da DF em uma interface com a argumentação pode revelar-se como um programa sólido para que compreendamos - por meio da depreensão dos mecanismos pré-conceptuais e conceptuais que subjazem aos processos de convencimento e persuasão humanos - de que maneira as vozes autorais mobilizam recursos linguístico-discursivos para favorecer determinadas perspectivas, obscurecer pontos de vista e incitar nos ouvintes determinadas representações da realidade.

\section{Referências}

BRETON, Philippe. A argumentação na comunicação. 2. ed. Bauru: EDUSC, 2003.

BYBEE, Joan. Language, usage and cognition. Cambridge: Cambridge University Press, 2010.

CIENKI, Alan. Frames, Idealized Cognitive Models, and Domains. In: GEERAETS, Dirk; CUYCKENS,
Herbert (org.) The Oxford Handbook of Cognitive Linguistics. New York: Oxford University Press, 2007, p. 170-187.

CROFT, William; CRUSE, Allan. Cognitive Linguistics. New York: Cambridge University Press, 2004.

CUNHA, Maria Angélica; BISPO, Edvaldo; SILVA, José Romerito. Linguística funcional centrada no uso: conceitos básicos e categorias analíticas. In: CEZARIO, Maria Maura; CUNHA, Maria Angélica (org.) Linguística Centrada no uso: uma homenagem a Mário Martelotta. Rio de Janeiro: Mauad X/FAPERJ, 2013, p. 13-39.

DE MULDER, Walter. Force Dynamics. In: GEERAETS, Dirk; CUYCKENS, Herbert (org.) The Oxford Handbook of Cognitive Linguistics. New York: Oxford University Press, 2007, p. 294-317.

DISHONG, Greta. Force-dynamic aspects of the genetically modified food debate. Dissertação de Mestrado. Case Western Reserve University, 2004.

FERRARI, Lilian. Introdução à Linguística Cognitiva. São Paulo: Contexto, 2011.

GEERAERTS, Dirk. Recontextualizing grammar: Underlying trends in thirty years of Cognitive Linguistics. In: Tabakowska, E. et al. Cognitive Linguistics in action: from theory to application and back. Berlin: De Gruyter, 2010, p. 71-102.

GONÇALVES-SEGUNDO, Paulo Roberto. Tradição, estabilidade e dinamicidade nas práticas discursivas: um estudo da negociação intersubjetiva na imprensa paulistana. Tese de Doutoramento. Faculdade de Filosofia, Letras e Ciências Humanas da Universidade de São Paulo, $2011 . \quad$ DOI: http://dx.doi.org/ 10.11606/T.8.2011.tde-25042012-161141

GONÇALVES-SEGUNDO, Paulo Roberto. A permeabilidade da Dinâmica de Forças: da gramática ao discurso. In: LIMA-HERNANDES, Maria Célia; RESENDE, Briseida Dôgo; DE PAULA, Fraulein Vidigal; MÓDOLO, Marcelo; CAETANO, Sheila Cavalcante (org.). Linguagem e cognição: Um diálogo interdisciplinar. Lecce: Pensa Multimedia Editores, 2015, p. 163-185.

GONÇALVES-SEGUNDO, Paulo Roberto; RIBEIRO, Rafaela Baracat. Envolvimento e empatia: a solidariedade construída nas colunas de aconselhamento em revistas. Revista do GEL, v. 13 , n. 2, p. 211-236, 2016. DOI: http://dx.doi.org/10.21165/gel.v13i2.835

HALLIDAY, Michael. Introduction to Functional Grammar. $3^{\underline{a}}$ ed. Revisado por Christian Matthiessen. London: Hodder Arnold, 2004.

LAKOFF, George. Women, fire, and dangerous things: What categories reveal about the mind. Chicago: University of Chicago Press, 1987. 
LANGACKER, Ronald. Cognitive grammar: a basic introduction. New York: Oxford University Press, 2008.

OAKLEY, Todd. Force-dynamic dimensions of rhetorical effect. In: HAMPE, Beate (org.) From perception to meaning: image schemas in Cognitive Linguistics. Berlin: Mouton De Gruyter, 2005, p. 443-473.

PERELMAN, Chaïm; Olbrechts-Tyteca, Lucie. Tratado da Argumentação: A Nova Retórica. São Paulo: Martins Fontes, 2002 [1958].

REBOUL, Olivier. Introdução à retórica. $2^{\underline{a}}$ ed. São Paulo: Martins Fontes, 2004 [1998].

TALMY, Leonard. Towards a Cognitive Semantics $v$. 1. Cambridge: MIT Press, 2000.

TOULMIN, Stephen. Os usos do argumento. $2^{\underline{a}}$ ed. São Paulo: Martins Fontes, 2006 [1958].

TOULMIN, Stephen; RIEKE, Richard; JANIK, Allan. An introduction to reasoning. $2^{a}$ ed. New York: Macmillan Publishing Company, 1984 [1978].

VAN EEMEREN, Frans; GROOTENDORST, Rob; HENKEMANS, A. Francisca. Argumentation: Analysis, Evaluation, Presentation. London: Lawrence Erlbaum Associates, 2002.

VAN EEMEREN, Frans; HOUTLOSSER, Peter; HENKEMANS, Francisca Snoeck. Argumentative indicators in discourse: A Pragma-Dialectical Study. Dordrecht: Springer, 2007.

\section{COMO CITAR ESSE ARTIGO}

GONÇALVES-SEGUNDO, Paulo Roberto. Orientação argumentativa e Cognição: a Dinâmica de Forças no debate acerca dos rolezinhos. Signo, Santa Cruz do Sul, v. 42, n. 73, jan. 2017. ISSN 1982-2014. Disponível em: <https://online.unisc.br/seer/index.php/signo/article/view/7924>. Acesso em: doi: http://dx.doi.org/10.17058/signo.v42i73.7924. 


\section{Anexos \\ Anexo $1(\mathrm{~T} 1)$ \\ Tais como são, os 'rolezinhos' atentam contra direitos coletivos}

\section{MAURO RODRIGUES PENTEADO. ESPECIAL PARA A FOLHA}

Por mais que nos solidarizemos com nossa juventude humilde que busca espaços para se relacionar e dar vazão ao seu amor e alegria, não é possível apoiá-la nessa onda recente de "rolezinhos" marcados em shoppings centers e outros locais privados com destinação específica.

É triste a ausência de opção de lazer para nossos jovens de camadas mais pobres. No entanto, os "rolezinhos", tais como vêm sendo marcados, atentam contra os direitos individuais e coletivos assegurados pela Constituição Federal.

Isso sem falar no direito também constitucionalmente garantido à propriedade e à livre

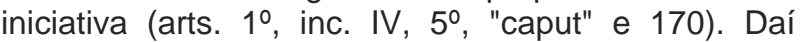
porque estão corretas as liminares concedidas pelo Judiciário aos shoppings - que estabeleceram multa aos participantes.

Os shoppings são empreendimentos privados abertos ao público especificamente para compras, lazer, diversão, passeio.

A maioria deles tem cinemas e praças de alimentação. Nenhum deles tem ainda uma "praça do rolezinho", modalidade de diversão muitas vezes conturbada por jovens infratores, ferindo o legítimo direito de pais, mães e filhos a um lazer sossegado e seguro que vão buscar nesses ambientes privados e protegidos.

Se o poder público não disponibiliza, como deveria, espaços próprios para o saudável congraçamento e encontro entre jovens, nem por isso os brilhantes moços que os organizam deixam de ter alternativas interessantes.

E todas elas são protegidas pela Constituição.

AVISO

$\mathrm{O}$ inc. XVI do art. 5ำ garante que "todos podem reunir-se pacificamente, sem armas, em locais abertos ao público, independentemente de autorização", bastando "prévio aviso à autoridade".

Ora, por que não organizar os encontros no sambódromo ou outros locais públicos? Os convocados pela internet não vão faltar. Meninos e meninas levam o som, comidas e bebidas (sem álcool de preferência). Aí a festa será "legal", no duplo sentido: com muita animação e sem riscos de liminares e multas.

Juridicamente, basta os organizadores enviarem cópia da convocação à prefeitura e à Secretaria da Segurança.

MAURO RODRIGUES PENTEADO é advogado, árbitro e professor de direito comercial da USP.

\section{Endereço da página:}

http://www1.folha.uol.com.br/fsp/cotidiano/14766 3-tais-como-sao-os-rolezinhos-atentam-contradireitos-coletivos.shtml

\author{
Anexo 2 (T2) \\ Liminar que proíbe encontro assegura 'direito à \\ segregação'
}

\author{
PEDRO ABRAMOVAY. ESPECIAL PARA A FOLHA
}

São raríssimos os casos em que a decisão do juiz não deve analisar com cuidado dois direitos distintos.

Por isso é tão difícil a tarefa de julgar. A lei provoca contradições entre direitos. Quase sempre.

O caso dos "rolezinhos" não foi diferente. Um juiz concedeu uma liminar afirmando que se os jovens da periferia levassem adiante sua intenção de comparecer em conjunto a shopping centers para realizar a prática do já famoso "rolezinho", seriam multados em $R \$ 10$ mil.

O próprio juiz admitiu que havia um conflito de direitos. O direito de manifestação dos jovens da periferia e o de propriedade dos donos do shopping. O juiz diz que o direito de propriedade deve prevalecer porque há outros espaços mais apropriados para manifestações.

Essa resposta do juiz veio em uma liminar. 0 que significa que apenas um lado foi ouvido: o lado dos donos de shopping. E só isso pode explicar o fato de se imaginar que o "rolezinho" pode ser feito nas ruas.

O que pedem os "rolezinhos"? Sem danificar o patrimônio e sem registros de furtos, jovens da periferia querem circular por espaços que the são proibidos. Espaços segregados. Segregados, até agora, não pela força do direito, mas porque não há nada ali que lhes seja acessível.

O grande problema da decisão é que ela assegura um direito à segregação.

Shoppings são espaços de livre circulação. Impedir a entrada de alguém em estabelecimento comercial por motivo de discriminação ou preconceito é crime.

Admitir que só algumas pessoas podem circular por lá, com policiais e oficiais de Justiça analisando quem pode ou não entrar, oficializa a discriminação.

$\mathrm{Na}$ verdade, não se trata apenas do conflito entre direito de propriedade e de manifestação. Tratase de uma nova agenda de desigualdade que não se encerra em programas de transferência de renda, mas com questão de como se cria um país de convivência e não de segregação.

Esses jovens querem ser ouvidos, ser vistos -aliás, não apenas os jovens da periferia vão ao shopping para serem vistos. E eles não estão sendo escutados. Tapar os ouvidos não ajuda a solucionar o problema, ao contrário, tende a criar novos.

PEDRO ABRAMOVAY é professor licenciado da FGV Direito Rio e diretor para a América Latina da Open Society Foundations.

\section{Endereço da página:}

http://www1.folha.uol.com.br/fsp/cotidiano/147665liminar-que-proibe-encontro-assegura-direito-asegregacao.shtm 